\title{
ATENAS, O OLIMPISMO À GUISA DE URBANISMO
}

\author{
GUY BURGEL ${ }^{1}$
}

R E S U M O Os Jogos Olimpicos de 2004 marcaram o coroamento de uma nova era iniciada na capital grega há mais de um quarto de século. O retorno a uma democracia reforçada, a vinculação à Europa política, a consciência da responsabilidade internacional assumida no Mediterrâneo oriental, nos Bálcãs e no vasto mundo através da marinha grega, confirmam Atenas em seu destino de "cidade global". Para além da funcionalidade com relação à natureza das provas esportivas ou o desenrolar das festividades, a escolha dos sitios olimpicos respondeu a uma vontade estratégica afirmada sobre a totalidade do espaço da região urbana e a um desejo de reconversão geral das infra-estruturas após os Jogos. O presente texto mostra que, mais do que em Barcelona, onde o direcionamento da cidade para seu porto foi o grande evento dos anos 90, a mutação aqui engajada é mais fundamental, posto que Atenas, capital continental, não foi jamais uma cidade litorânea: desde a Antiguidade, o Pireu e suas bacias contribuintes constituem uma entrada maritima descentrada e a vocação da costa foi sempre mais balneária do que verdadeiramente urbana.

P A L A V R A S - C H A V E Atenas; Olimpiadas; urbanismo.

\section{INTRODUÇÃO}

O anúncio, em setembro de 1997, da escolha de Atenas como sede das Olimpíadas de 2004 confortou a capital grega em seu destino contemporâneo, dividida entre o enraizamento do mito (a Acrópole, o Parthenon), o intercâmbio mundializado de um país novo e uma cidade que há muito adotara ares latino-americanos. ${ }^{2}$ Desde sua refundação em 1830 na nova Grécia liberta do jugo otomano, Atenas, com efeito, nunca deixou de reivindicar seu apego à Antiguidade, a seus valores estéticos e monumentais, sua criação da democracia e da constituição urbanas e sua aspiração à modernidade, nas virtudes da internacionalização das sociedades, de reestruturação contínua das construções, para não falar do caos urbanístico instaurado em sua espontaneidade criadora. Segundo as épocas, estas tensões antagônicas associaram-se ou opuseram-se. Durante todo o século XIX até o fracasso da "Grande idéia" (a conquista da Ásia Menor) em 1922, Atenas havia tentado viver ao mesmo tempo suas aberturas exteriores, seu zelo pela legitimidade histórica e seu testemunho de uma Europa das Luzes no Oriente: o helenismo econômico e social triunfante estava alhures, em Esmirna, Alexandria, ou mesmo em Tessalônica, mas os palácios neoclássicos faziam reviver a Grécia antiga ao longo das amplas avenidas desenhadas pelos arquitetos bávaros de Othon, primeiro rei da nação livre. Da "catástrofe" da Ásia Menor à queda dos coronéis (1974), Atenas viu o recuo nacional, mas não o fim de seus males urbanos: a crise dos anos 30, a ocupação nazista, a guerra civil, a democracia incerta fecharam os horizontes econômicos, sociais e políticos, mas a cidade foi a cada passo perturbada pela instalação dos refugiados trocados com a Turquia, pelo êxodo rural maciço e sobretudo pela renovação espontânea dos bairros centrais e pela explosão da habitação informal nas periferias da aglomeração.
1 Tradução de Lucia Reis.

2 Ver sobre o tema, G. Burgel, Le miracle athénien au XXème siècle, 2002; e G. Burgel e Z. Demathas, La Grèce face au troisième millénaire, 2001. 
Nesta história rapidamente esboçada, os Jogos Olímpicos de 2004 marcaram o coroamento de uma nova era iniciada na capital grega há mais de um quarto de século. $\mathrm{O}$ retorno a uma democracia reforçada, a vinculação à Europa política, a consciência da responsabilidade internacional assumida no Mediterrâneo oriental, nos Bálcãs e no vasto mundo através da marinha grega, confirmam Atenas em seu destino de "cidade global". Ao mesmo tempo, emergem preocupações novas e insólitas na bacia do Ático, de proteção do meio ambiente, de desenvolvimento sustentável, de conservação do patrimônio, ao menos daquilo que dele ainda resta. Em grande medida, os Jogos identificam-se a pensamentos inovadores e sua preparação tornou-se um acelerador de sua materialização. E como é preciso sempre um símbolo e uma imagem forte, a nova extensão, inteligente e surpreendente, que acaba de realizar Mario Botta para a sede do Banco Nacional, integrando uma parte dos locais de Themístocles (século $\mathrm{V}$ a.C.) no conjunto neoclássico do século XIX restaurado e situado na praça Kotzia (banco, antiga agência de correios), onde devia julgar-se a chegada das provas de ciclismo, é uma figura emblemática da Atenas olímpica: cultural e contemporânea.

\section{O CATALISADOR OLÍMPICO}

Como de hábito, se a organização dos Jogos Olímpicos mobilizou toda a atenção do Estado e da opinião pública durante vários anos, e se a agitação dos preparativos perturbaram dia e noite toda a vida da capital por meses, as obras diretamente ligadas ao evento pareciam extraordinariamente limitadas em número e extensão. Mas, desde a origem, as autoridades insistiram no esperado efeito de "alavanca" sobre o conjunto dos problemas urbanos. Kostas Liaskas, vice-presidente da Comissão Organizadora dos Jogos Olímpicos e presidente da Câmara Técnica da Grécia, declarava com grandiloqüência em 1997: "Todas as obras, as ações e consequiências que prevemos deveriam ter sido consideradas pelo Estado há décadas. A organização dos Jogos dá ocasião a um despertar de Atenas em muitos domínios e a um novo enfrentamento dos problemas da cidade no quadro da região metropolitana”.

De fato, para além da funcionalidade com relação à natureza das provas esportivas ou o desenrolar das festividades, a escolha dos sítios olímpicos respondeu a uma vontade estratégica afirmada sobre a totalidade do espaço da região urbana e a um desejo de reconversão geral das infra-estruturas após os Jogos.

Com os equipamentos colocados na baía de Falero e as infra-estruturas programadas em Aghios Kosmas, em ligação com a preparação dos terrenos liberados pelo fechamento do antigo aeroporto de Hellenikon, trata-se, sobretudo, de um deslocamento da cidade em direção ao mar. Mais do que em Barcelona, onde o direcionamento da cidade para seu porto foi o grande evento dos anos 90, a mutação aqui empreendida é mais fundamental, posto que Atenas, capital continental, não foi jamais uma cidade litorânea: desde a Antiguidade, o Pireu e suas bacias contribuintes constituem uma entrada marítima descentrada e a vocação da costa foi sempre mais balneária (vilegiatura em Novo Falero no fim do século XIX, praias e marinas do Velho Falero em Vouliagmeni na segunda metade do século $\mathrm{XX}$ ) do que verdadeiramente urbana.

A amplitude dos investimentos (mais da metade da despesa total foi feita nos $6 \mathrm{~km}$ de costa da baía de Falero) e a natureza e a concepção dos equipamentos respondem a um projeto de abertura histórica para o mar. À construção futurista do estádio de vôlei de 
praia, e à reutilização do Estádio da Paz e da Amizade para os fins do voleibol, junta-se a ambição explícita do restabelecimento da ligação da cidade com a água: nova localização da estrada litorânea com espaços verdes lineares de proteção visual e sonora, chegada do bonde, vasto viaduto-promenade ligando as infra-estruturas, proteção contra os riscos de inundação por gigantescas obras de canalização e de cobertura do Cefiso e do Ilissus, espaços para museus - que associam um velho museu militar a parques e restaurantes, novos prédios de exposição naval e de arte moderna e um aquário, do qual esta capital de um império marítimo estava curiosamente desprovida. Vitrine dos Jogos Olímpicos, a baía de Falero foi destinada a tornar-se a fachada da cidade para o mar e o mundo.

$\mathrm{Na}$ outra extremidade, a Noroeste, sobre as inclinações do Parnes, a $23 \mathrm{~km}$ do centro da cidade, num terreno de 120 hectares, foi edificada a Vila Olímpica. Neste lugar a situação ainda é mais que simbólica: reequilibrar Atenas em direção a um oeste desfavorecido pelas implantaçôes industriais e operárias, contrariamente à lógica clássica das cidades européias, para revalorizar uma zona que foi diretamente atingida pelo terremoto devastador de setembro de 1999. As realizaçōes deveriam estar à altura desta ambição: um quarteirão "ecológico", utilizando as energias novas, em que as infra-estruturas, o que é uma grande inovação para Atenas, foram concebidas antes das construções funcionais, ligações rápidas graças à rede, em renovação, dos trens de subúrbio. Assim como para todos os outros equipamentos olímpicos, o conjunto das instalações (residências para 15 mil atletas, zona internacional com centro comercial, campo para treinamentos esportivos no meio da vegetação mediterrânea) deve ser convertido em bairro habitacional com 2.300 alojamentos sociais - o que também é uma exceção nos bairros populares da capital, pelo estatuto jurídico e a densidade de ocupação do solo. O espírito olímpico transformaria os hábitos sociais e morfológicos de Atenas?

Diante desses dois campos estratégicos, as outras localizações previstas para os jogos podem parecer mais limitadas ou mais funcionais. Ao Norte, em volta do estádio olímpico já existente, o centro aquático (natação, pólo aquático), o velódromo, o ginásio, o centro de tênis e sobretudo a cidade da imprensa, dispersa em muitos prédios, para evitar o congestionamento, reforçam a vocação lúdica de um quarteirão aéreo em cadeia entre os subúrbios burgueses do Nordeste e as antigas zonas industriais em reconversão no Noroeste. No golfo de Eubéia, não muito longe do local histórico de Marathon, a base náutica de Eskinia (caiaque e canoagem) mexeu sobretudo com as consciências ecológicas e suas perturbações sobre um ecossistema sensível (pássaros migrantes) ou emocionou os meios esportivos com as condições das provas (ventos, meio marítimo). Mas em todo lugar o mais importante continua a ser a reutilização dos investimentos, de que os diferentes centros de imprensa dão uma idéia, como os inventários de Jacques Prévert: ${ }^{3}$ uma escola de polícia, os serviços administrativos do Ministério da Educação, uma cidade universitária.

De fato, para além da atração dos espectadores e do boom econômico que provoca a preparação dos Jogos (700 milhões de euros estimados de 2001 a 2004, apenas no que se refere às empresas de construção), é realmente o relançamento e sobretudo a redefinição da ação pública sobre a cidade que eram esperados na capital, prioritariamente. Sem dúvida, com uma preocupação de mobilização nacional e de simbolismo histórico, certas provas foram descentralizadas: o futebol nas metrópoles de província (Tessalônica, Patras, Volos, Iraklio), o arremesso de peso em Olímpia. Mas por trás desta maquiagem clássica, os Jogos Olímpicos em Atenas sancionam em todas as escalas a volta da centralidade urbana e os desafios que lhe são lançados.
30 poeta francês Jacques Prévert fez versos misturando livremente palavras e imagens de objetos sem relação aparente entre si. Uma expressão nasceu: trata-se de "inventários a la Prévert". 


\section{DA BALCANIZAÇÃO À MUNDIALIZAÇÃo}

Com menos de dois séculos de existência, a capital grega apresenta, excepcionalmente, um bom resumo da história urbana européia. Sem dúvida, é útil procurar aqui a continuidade do patrimônio na sua materialidade psíquica do espaço da cidade: escolhida em 1834 pelo alcance simbólico de seu nome, Atenas é uma cidade nova, construída à americana, na qual o vestígio da Antiguidade permaneceu por muito tempo, até os últimos anos, um monumento isolado na desordem dos prédios contemporâneos e na circulação automobilística. Aqui, a idade industrial, sem dúvida, praticamente não ocorreu ou, ao menos, foi parcial e tardia: "proto-industrialização" do Pireu em torno do têxtil, da metalurgia e da química de base, no fim do século XIX; proliferação da indústria leve dos anos 50 aos 70, no século XX. Em Atenas, o consumo sempre foi maior que a produção: a definição de Jean Delumeau sobre Roma poderia perfeitamente lhe ser aplicada: "cidade de alfaiates mais que de tecelóes".

Mas as convergências com a história geral devem ser buscadas para além das simples percepções paisagísticas ou da análise das funções urbanas. Em sua singularidade, e na força que dá o resumo das periodizações breves, Atenas oferece uma perspectiva sobre as seqüências de construção das escalas da cidade, da produção dos espaços materiais nas redes de influência nacionais e longínquas. Em 2004, quando a capital grega acolhe o acontecimento mundial dos Jogos Olímpicos, a oportunidade não é mal escolhida para medir o caminho percorrido em mais de um século, desde que Pierre de Coubertin organizava em Atenas em 1896 os primeiros jogos da era contemporânea. O espírito olímpico como forma de urbanismo não é somente uma aposta política das autoridades gregas, é um modo de leitura destas "cidades globais" nas quais o lúdico se torna motor da economia, e o mundo, o campo de ação.

\section{INTERNACIONALISMO MEDITERRÂNEO E URBANISMO PROVINCIANO: 1834-1922}

Em Atenas, o século XIX começou tarde e se prolongou para muito além da Primeira Guerra Mundial. Capital sob influência, Atenas se desenvolve lentamente durante décadas, à sombra de uma diplomacia que falava francês, mas onde as potências tutelares, ao lado da França, são a Inglaterra marítima e a Rússia ortodoxa. Aparentemente mais distantes, o Império Austro-Húngaro e a Alemanha são testemunhas atentas que estendem sua influência nos Bálcãs, inclusive através dos laços pessoais e familiares. O fundador da dinastia grega, Othon, é bávaro. E no século XVIII, uma das primeiras empresas industriais na península, a cooperativa de lençóis de Ambelakia, tinha sido desenvolvida pelos Mavros Schwartz (os "Negros", de Viena) na Tessália. Todos assistem e participam com prudência, tendo ao fundo despertares nacionalistas e dos direitos dos povos a cuidar de si próprios, diante do desmantelamento do Império Otomano, "o homem doente da Europa”, do qual o novo Estado grego é o feliz beneficiário, em termos de anexações sucessivas: Tessália e Arta (1881), Macedônia, Épiro, Egeu oriental, a partir das guerras balcânicas (1913).

Mas no recenseamento de 1907, Atenas tem ainda apenas 250 mil habitantes numa Grécia que ultrapassa 2,6 milhōes de cidadãos (9,4\% da população total). Apesar da força do Estado e de sua administração centralizada, apesar do peso da organização bancária 
e de seu privilégio de emissão monetária (o Banco Nacional foi criado em 1841), as razões de debilidade demográfica e econômica da cidade restam a ser ainda identificadas na desarticulação das escalas territoriais do país e dos espaços de referência na nação grega. Atenas é a capital política de um pequeno reino fechado, na extremidade da Europa. Mas o helenismo, aquele helenismo vivo, o das trocas comerciais e culturais, mediterrâneas e continentais, está no exterior, nas grandes cidades multicomunitárias de uma Turquia decadente, mas imensa: Tessalônica, Esmirna, Alexandria. Sozinha, no meio do Egeu, Ermoupolis, na ilha de Siros, com sua burguesia cosmopolita, tentou durante algumas décadas impulsionar o império marítimo de um negócio internacional (canteiros navais, fiaçôes), antes de ser reduzida à mediocridade pela dominação confinada de Atenas. A dimensão dos espaços da cidade não está à altura nem dos sonhos geopolíticos das potências estrangeiras, nem das ambiçôes nacionais de herança direta da cidade da Antiguidade.

$\mathrm{Na}$ sua construção material, a capital revela essas mesmas contradições. De Kleantis a Schaubert, os urbanistas do rei Othon conformam a cidade, pelo menos seus bairros de aparato, à imagem da Europa das Luzes e de um neoclassicismo inspirado no Parthenon e importado para a atmosfera e cultura orientais - projeto majestoso das avenidas que assegura ainda uma certa fluidez na circulação do centro da Atenas contemporânea, desenho das praças que, apesar de sua ornamentação de palmeiras, imprimem no espaço a marca do poder e da razão (praça Omonia, da Concorde, Syntagma, da Constituição), arquitetura dos palácios e dos prédios públicos (Parlamento, Biblioteca, Academia, Universidade, Observatório) destinada a surpreender os espíritos e a estimular as seguranças nacionais.

Mas as realidades não estão mais em uníssono com essas pretensões grandiosas. Os edifícios monumentais permanecem muito tempo isolados, na expectativa improvável de absorção urbana que, em si, assegura a continuidades das fachadas, a presença da rua e a existência da cidade. Se a intelligentsia e a burguesia de negócios, não se furtam ao investimento de prestígio na capital nacional, elas não residem ali a não ser periodicamente, porque seus lucros os levam, sabe-se, para outros lugares. E para dar a ilusão da crença, ou melhor, mostrar que eles a dominam à distância, os engenheiros são constrangidos a traçar planos de extensão da cidade que duram anos antes de ter alguma consistência. Coincidência dos tempos ou permeabilidade das idéias e da informação, aplica-se aqui a ensanche que fez Cerda em Barcelona, mas sem o gênio e a dedicação econômica da capital catalá. Atenas é uma província que se faz de grande dama.

O internacionalismo criava a ambigüidade de Atenas. Paradoxalmente, o internacionalismo vai fundar sua unidade contemporânea reencontrada. Logo após a Primeira Guerra Mundial, os aliados jogam a Grécia na aventura da Ásia Menor, na conquista desesperada da "Grande idéia", para fazer do Egeu um lago heleno. Não contam com o levante do "jovem turco" (Mustapha Kemal) e as divergências de interesses entre a França e a Inglaterra que desejavam há muito tempo as fabulosas riquezas petrolíferas do Oriente Médio. A Grécia está entregue à sua sorte, logo constrangida pelo Tratado de Lausanne (1922) a abandonar suas pretensóes territoriais e a trocar as populaçôes gregas das cidades e campos pelos últimos habitantes turcos da Hélade insular e continental. Apenas a Trácia grega e Constantinopla (Istambul) escapam desta "purificação étnica" organizada sob a égide da Sociedade das Nações. De fato, esta "catástrofe", humanamente e nacionalmente humilhante e mutilante, se mostra fundadora da identidade urbana de Atenas: ela "recentraliza" de forma durável a capital na nação, assegura seu crescimento demográfico, econômico e espacial. 


\section{A CONSTRUÇÃO DA CAPITAL NACIONAL: 1922-1974}

Em meio século, Atenas passa de 450 mil habitantes (1920) para 2,5 milhões de residentes. Em 1971, já há perto de 3 milhões de habitantes na região urbana que se desenha de Corinto ao cabo Sunion e de Tebas a Kalkis. Período muito curto, enfim, que soma as breves esperanças de reformas esclarecidas de Eleftherios Venizelos, as perspectivas sombrias do regime militar de Metaxas (1936), os anos terríveis da ocupação nazista, os combates fratricidas da guerra civil (1945-1949), as incertezas políticas da reconstrução (1950-1967), antes de mergulhar, de forma totalmente anacrônica em relação à Europa, na aventura da ditadura dos coronéis (1967-1974). Atenas ganha nessa época sua legitimidade funcional e seu destino morfológico.

O primeiro resultado é a construção de um espaço econômico centralizado na capital política do país. Desde a ruína das ambiçoes externas e o fechamento dos horizontes marítimos e continentais, a crise mundial dos anos 30 aperta um pouco mais, e não há mais então nem hesitação, nem outra via a não ser a construção de um mercado nacional da produção e do consumo. Materialmente, os refugiados na Ásia Menor, fortes na sua cultura e tradições artesanais, mas sobretudo desejosos em se integrar socialmente de imediato na sua nova pátria, tomam a iniciativa e se tornam a força de manobra do processo. Cerca de 250 mil, um sexto do efetivo total, fixam-se ou são envolvidos na política governamental ou são atraídos pela política governamental para a aglomeração ateniense. Encontramos um bom número deles entre os formadores de mão-de-obra da indústria têxtil que se desenvolve nos subúrbios do Norte da capital, com topônimos que evocam os sonhos perdidos (Nova Iônia, Nova Filadélfia).

Mas em geral, esta aventura envolvendo os egressos da Ásia Menor, cujos testemunhos são ainda muito vivos na Atenas dos anos 60 - bairros comunitários, roupa feminina, práticas culinárias -, constitui apenas sinais de um encadeamento de mecanismos que fazem de Atenas ao mesmo tempo o ateliê e a vitrine do desenvolvimento econômico grego. Destituídos de verdadeiros espaços de fontes de energia e de matérias-primas autóctones que estabeleçam as grandes tradições das regiōes industriais, mas conscientes das vantagens oferecidas pela capital de um Estado centralizado, com suas redes bancárias e de comunicação, sua administração e sua segurança interna consideráveis em períodos de turbulência, as forças sociais e políticas do país escolhem deliberadamente construir uma estrutura econômica moderna no coração de seu dispositivo político e logístico. Não é mais, entretanto, e já há muito tempo, desde a anexação das províncias do Norte (Macedônia, Épiro e Trácia), seu centro de gravidade demográfico e produtivo. Antes mesmo do que esses movimentos de países desenraizados pela miséria do campo e as exações da guerra civil, e o deslumbramento pelas luzes da cidade de que descrevemos sempre o descontrole nos anos 50, é o abandono das elites de província (industriais sem condiçóes no mercado, comerciantes sem fregueses, funcionários sem futuro) que prepara o terreno, e assegura na capital o reinvestimento das economias e das esperanças em termos de toda a nação.

A singularidade da história ateniense quis que esta elaboração econômica e social de um território urbano fosse intimamente ligada à construção material da cidade e à invasão generalizada da bacia de Ática. Muito mais que a haussmanização parisiense que, mesmo acompanhando a ascensão da burguesia industrial no século XIX, permanece limitada no espaço e na funcionalidade da capital francesa, as transformações da urbanização aparecem em Atenas como motores no desenvolvimento econômico. Além da rapidez dos 
ritmos do crescimento urbano, a razão também reside no déficit do poder público, que constrange as forças sociais a participar direta e completamente na edificação de seu quadro de vida. Densificação das zonas centrais, autorizada pela elevação contínua dos coeficientes de ocupação do solo, mas também pelo sucesso astucioso do procedimento da "contra-troca" (antiparokhi), colonização aceita, apesar de sua ilegalidade, por meio das moradias populares em todos os lados periféricos da bacia; regularizações inteligentes, na medida das oportunidades políticas, desses bairros espontâneos que acabam fazendo parte dos ciclos urbanos da mutação morfológica e do enriquecimento coletivo: em algumas décadas, Atenas preenche seu espaço. A nostalgia dos gêneros de vida antigos se instaura. Os atrativos do meio ambiente natural se apagam sob o cimento e a poluição. Mais inexoravelmente ainda, a carência dos serviços públicos, principalmente em matéria de transportes urbanos, é o preço deste urbanismo privatizado. Mas seu milagre é o de ter assegurado a uma cidade sua situação social e geográfica legítimas.

E a organização material da aglomeração é a imagem desta construção paradoxal de um espaço nacional fechado. O Centro, extraordinariamente restrito para uma capital com esta importância, é todo contido no pequeno triângulo de uma centena de hectares. Ao Norte da Acrópole, limitado pelas praças Syntagma e Omonia e a rua Ermou: ministérios e administrações públicas, sedes sociais de grandes empresas, comércio de varejo, atividades culturais e turísticas aí se acumulam numa mistura funcional insólita com uma grande multidão humana incansavelmente renovada. Com exceção de algumas ilhotas de irredentismo pireu entre o porto e o teatro municipal, e as zonas industriais da planície de Cefiso, todo o resto é formado por bairros residenciais estendidos com monotonia e perseverança por dezenas de quilômetros. Apenas a grande dessimetria meridiana, que opõe desde o século XIX o palácio real a Leste e a usina a gás a Oeste, corta a bacia de Ática, rejeitando os bairros populares nos flancos de Aigaleo e reservando para a burguesia os vales do Pentélico e do Himeto, de Kifissia à Glifada.

Numa leitura da história um tanto reducionista, o golpe de estado militar de 1967 e a instauração de um sistema ditatorial marcam o apogeu e o termo desta construção fechada, como a breve conquista da Ásia Menor no início dos anos 20 foi o buquê final das ambiçōes imperialistas da nação. A Grécia dos "helenos cristãos" e das "preferências nacionais" parece então se voltar para uma ortodoxia ultrapassada, e a uma autarquia econômica de uma outra era. A especulação imobiliária, encorajada pelas práticas populistas do regime, atinge níveis desiguais em Atenas e se difunde em todo corpo social. Mas logo as contradições aparecem. A abertura do país ao grande turismo internacional, as implicações da marinha mercante grega no comércio mundial, notadamente com a entrada da China no mercado planetário, as recomendaçóes deflacionistas do Fundo Monetário, mal compreendidas pela população, se somam aos desmandos sangrentos do regime (a repressão da Escola Politécnica em novembro de 1973) e às aventuras externas sem futuro (a invasão de Chipre em julho de 1974), para fechar um novo período sombrio da história grega, mas sobretudo completar um ciclo urbano.

\section{A CIDADE GLOBAL A PARTIR DE 1974}

Com efeito, por mais de um quarto de século, com o que os cortes políticos representam de arbitrário numa periodização social, que prefere as continuidades às rupturas, a capital grega está engajada numa nova direção. A inversão é sobretudo humana. $\mathrm{O}$
4 Fórmula de construção em que um proprietário de terras ou de habitação cede seus direitos de propriedade a um arquiteto ou um empresário, deixando a cargo destes últimos a construção de um imóvel e a restituição ao antigo proprietário, sob a forma de apartamentos, de uma porcentagem definida do valor da nova construcão. A cota do antiparokhi variou mais ou menos entre $20 \%$ na periferia e até mais de $60 \%$ na região central. 
início do exílio dos intelectuais na Europa ocidental (França, Alemanha, Inglaterra), ainda que em número limitado, traz para Atenas idéias originais e práticas urbanas diferentes. Aos olhos da burguesia tradicional, a instalação do compositor Mikis Theodorakis no bairro popular de Koukaki, aos pés da Acrópole, é um escândalo, mas prefigura novas atitudes das elites para a conservação do patrimônio e a apreciação residencial dos bairros centrais.

A inversão das conjunturas migratórias tem um outro alcance demográfico e de tradução menos momentânea. De terra clássica de emigração mediterrânea, a Grécia se torna um país de acolhida. Trata-se da volta dos trabalhadores migrantes que a crise econômica e a desindustrialização trazem de volta da Europa (Alemanha, Bélgica). Com suas oportunidades imobiliárias e o desenvolvimento das atividades terciárias (comércio, empresas de transporte e de turismo), Atenas seduz muito aqueles que não tinham laços anteriores com a cidade. Mas é o fim do comunismo nos Bálcãs (Albânia, Iugoslávia), no Leste europeu e na ex-União Soviética que afirma verdadeiramente a era da mudança. Com sua prosperidade aparente, sua paz civil, sua demografia envelhecida e suas necessidades crescentes de mão-de-obra (construção, obras públicas, serviços domésticos e turísticos, marinha mercante), a Grécia, e em primeiro lugar sua capital, despertam certamente os mesmos apetites que Bizâncio exerceu nos cavaleiros ocidentais da quarta cruzada: a cobiça e o desejo de instalação. Apesar de seu velho fundo nacionalista e sua desconfiança crescente em relação a populaçóes alógenas sempre suspeitas de trazer insegurança e desvio, a sociedade grega tolera, por interesse mais do que por hospitalidade, estes aportes estrangeiros. Do pessoal de serviço das camadas dominantes às centenas de milhares de trabalhadores manuais nos canteiros dos Jogos Olímpicos, todos se abrem - especialmente a capital grega - para o mundo, do Curdistão à Polônia e das Filipinas à Ucrânia. Pela primeira vez na história, a diáspora não é externa, mas instala-se, múltipla, no interior do espaço urbano.

As aberturas institucionais e políticas vieram reforçar essas diversidades sociais e humanas. Evidentemente, a mais notável é a entrada na Comunidade Européia. Temida e mitificada, ela suscitou com freqüência na opinião movimentos de hostilidade tanto mais paradoxais quanto as implicaçôes econômicas foram favoráveis ao país. Se a política agrícola comum deu aqui como em outros lugares o tom, despertando no campo grego a modernidade produtiva e as reivindicaçóes corporativas, Atenas tirou certamente disso o partido mais visível, ainda que a repartição geográfica dos "pacotes Delors" tenha sido tão bem guardada quanto os segredos de Defesa. As entradas viárias da capital, o início de uma rede de metrô, esperada há décadas e implantada em 2000, a transferência em 2001 do aeroporto de Spata no Mesogeu, o gigantesco contorno da cidade pelo Norte, concluído para a abertura dos Jogos Olímpicos ("Via Atiki”), mobilizaram energias e recursos para além da medida das capacidades nacionais. São sobretudo exigências funcionais e símbolos identitários que qualificam uma posição de metrópole internacional. A infraestrutura e a imagem tornam-se atributos do poder mundial da cidade.

Atenas aspira com efeito cada vez mais ultrapassar seu papel de capital nacional que a condenava volta e meia a esmagar a província ou nela descentralizar os investimentos. A opinião grega e os habitantes são evidentemente sensíveis às demonstrações de notoriedade da cidade (manifestações esportivas, acontecimentos culturais, colóquios, visitas de chefes de Estado estrangeiros) para se orgulhar ou queixar-se da perturbação da vida cotidiana. Os governos parecem mais inclinados a sublinhar o papel de mediador nos conflitos regionais ou mundiais. Apesar da dolorosa ocupação de Chipre 
e o status contestado do espaço aéreo Egeu, a normalização das relações com a Turquia é um dado a longo prazo. Do discurso histórico de Constantino Caramanlis em 15 de agosto de 1974, rejeitando a idéia de uma guerra com o vizinho otomano, à abertura esclarecida de Georges Papandreou, o ministro do Exterior do governo Simitis até as últimas eleiçôes legislativas da primavera de 2004, à solidariedade humana diante dos terremotos do mar de Marmara e de Atenas no verão de 1999, a continuidade se impóe. De forma mais extensa ainda, a capital grega, cuja situação geográfica podia parecer mais marginal que aquela da Tessalônica, no momento do desaparecimento da cortina de ferro, consegue se instaurar no conjunto dos Bálcãs e no Mediterrâneo oriental, como uma ponte entre o Norte e o Sul, o Leste e o Oeste. De novo, na mundialização da troca econômica e política, o posicionamento geral importa menos que o lugar estratégico da cidade.

$\mathrm{E}$ as transformações das materialidades urbanas se colocam em uníssono. A cidade já ultrapassara, por sua extensão contínua, os cortes que limitam a bacia de Ática em direção a Oeste (Dafni e Corinto), Norte (Inofita e Tebas) e Sudeste (Vouliagmeni e o cabo Sounion). Mas os dinamismos espaciais têm a partir de agora uma outra amplidão. As funções centrais (sedes sociais, bancos) não param de se estender sobre o eixo meridiano que cerca o tecido urbano, em direção ao Sul (avenida Sygrou) e sobretudo ao Norte (avenida Kifissias), dando forma de passagem a prédios de vidro e de luz, atividades de distração e centros comerciais luxuosos, voltados para o atendimento residencial da clientela abastada. A transferência do aeroporto de Hellenikon do outro lado do Himeto e os equipamentos programados para os Jogos Olímpicos agregam a essas tendências clássicas da centralidade uma dimensão nova. Voltada para a proximidade aérea internacional, a pressão urbana (hotéis, escritórios, logística) não se situa mais na continuidade do front de aglomeração, mas investem na planície do Mesogeu, que se torna o principal campo de especulação fundiária na capital. Simultaneamente, as infra-estruturas olímpicas mais prestigiadas querem virar para a frente do mar uma cidade que foi sempre continental: chegada do novo bonde, reorganização lúdica da baía de Falero, parque natural e esportivo do antigo terreno de aviação de Hellenikon. De uma organização funcional simples, Atenas passa a ter uma complexidade espacial característica das cidades mundiais.

Ao mesmo tempo, a velha centralidade ateniense, atingida em suas prerrogativas direcionais, inventa novas legitimidades culturais. Os pontos arqueológicos em torno da Acrópole são enfim reunidos num itinerário para pedestres. Os edifícios neoclássicos que sobrevieram à picareta dos demolidores são restaurados e valorizados. A arquitetura pósmoderna se alia com felicidade ao vestígio antigo: sob a inspiração de Mario Botta, os restos do cinturão de Temístocles são reincorporados ao conjunto histórico da sede do Banco Nacional. A partir de agora, o Centro é visto e consumido, conformando esta aliança sutil do local e do global que funda a cidade hoje.

\section{AS TRÊS IDADES DAS CAPITAIS EUROPÉIAS}

Para além desta reconstrução esboçada de fases históricas da Atenas contemporânea, a questão continua a ser sua significação geral sobre as periodizações da grande cidade na Europa. Não é certo que a sucessão simples industrialização-pós-industrialização não seja por demais funcionalista e não convenha melhor às conurbações manufatureiras do que às capitais políticas e culturais do velho continente, em que ela negligencia as autonomias 
essenciais das sociabilidades e das morfologias materiais, privilegiando assim o que foi nelas uma transformação mais ou menos presente e mais ou menos tardia: a atividade de produção.

O exemplo ateniense sugere melhor uma sucessão de três ciclos cujo aparecimento e consistência dependem das particularidades locais e das histórias nacionais. O primeiro é herdado do cosmopolitismo da Europa das Luzes. Ele se manifesta pelo internacionalismo das idéias, até mesmo pela circulação de materiais e indivíduos, que no entanto permanece limitada às camadas culturalmente favorecidas das sociedades urbanas. A organização e o embelezamento da cidade imprimem as marcas territoriais que podem sobreviver às mutações econômicas e técnicas (a haussmanização de Paris).

A segunda era corresponde à afirmação do Estado-nação, à consolidação da economia industrial e à instauração de redes urbanas hierarquizadas. $\mathrm{O}$ urbanismo se apaga em geral diante do crescimento e os equilíbrios - ou os desequilíbrios - regionais, nas dimensões internacionais. Enfim, a fase atual de mundialização perturba de novo estas configurações bastante estáveis dos territórios. Prioridade aos interesses nacionais e descentralizaçôes controladas importam menos que o posicionamento das capitais nas trocas financeiras, culturais e humanas do planeta. Nesta perspectiva, o gesto arquitetural, a infra-estrutura monumental retomam seu significado. Nisto a lição ateniense guarda sua virtude iniciática naquilo que ela representa de urbanização contemporânea: o mito e o gigantismo, o patrimônio e a modernidade, o local e o mundial.

\section{A REGENERAÇÃO URBANA}

Ameaçados pelo terrorismo, pela falência econômica ou pelos atrasos técnicos, os Jogos Olímpicos de Atenas em agosto de 2004 deveriam ser um acontecimento excepcional. Em primeiro lugar, porque o espírito olímpico está ligado à Grécia e à sua capital. Do mito da paz e da força inspirado na tocha acesa, em meio a um cenário de túnicas gregas atravessado por um sábio jogo de espelhos óticos ao sol de Olímpia, no estádio antigo ressuscitado em 1896 por Pierre de Coubertin para os primeiros Jogos da era contemporânea, a filiação histórica aparece ainda mais legítima do que em Sidney, Atlanta, ou mesmo em Barcelona. Mas é para propor um novo desafio: a organização de uma manifestação agora mundial - num planeta com mais de 6 bilhóes de habitantes - para uma pequena nação (10 milhões de gregos) e uma grande cidade (3,3 milhões de atenienses, na cidade, e 4,5 milhôes na região urbana), que está de toda maneira longe do gigantismo do México, de Seul, ou mesmo de Moscou. De fato, estes paradoxos da história e da geografia se encontram num mesmo desafio: aproveitar os Jogos para regenerar uma cidade que não tem dois séculos de existência. Mais ainda do que na capital da Catalunha, o espírito olímpico se torna uma arma do urbanismo.

Nas transformações largamente espontâneas da capital grega ao longo do último meio século, as carências dos transportes públicos são o sinal mais evidente da ausência de pensamento global. Se não iniciaram o salto salutar, os Jogos Olímpicos aceleraram a tomada de consciência e a organização dos investimentos necessários. Até o final dos anos 90, as infra-estruturas são singularmente limitadas para uma cidade desta importância e extensão: um aeroporto internacional, com grande movimento de linhas regulares e curtos trajetos, bloqueado em plena cidade entre o mar e a montanha, uma antiga via férrea do final do século XIX transformada em metrô urbano descendo dos subúrbios ao Norte 
(Kifissia) para o Pireu, uma frota de ônibus precários e poluidores, mergulhados num mar de carros particulares, muito pouco desencorajados pelas limitações de circulação alternada no Centro. O cúmulo do paradoxo é atingido quando as grandes vias que penetram o interior da nação em direção à Tessalônica ao Norte e Patra a Oeste tornam-se auto-estradas urbanas, servindo de corredor expresso metropolitano, essencialmente meridiano. Não se resolve com tudo isso o grande desafio da mobilidade ateniense: as comunicações entre os bairros residenciais do Leste e as zonas de atividade do Oeste.

O início do novo milênio vê incontestavelmente um retorno espetacular, mesmo se as infra-estruturas organizadas são previstas e anunciadas há décadas. $\mathrm{O}$ fechamento do aeroporto de Hellenikon, a exploração, conseguida depois de alguns meses de inevitáveis ajustamentos, da plataforma ultra-moderna de Eleftherios Venizelos, em Spata, no Mesogeu, abrem o tráfego aéreo, liberam o céu de Ática e terrenos cobiçados à beira-mar. Os temores quanto à acessibilidade medíocre do novo aeroporto a partir da cidade revelaramse sem fundamento, mesmo que a ligação ferroviária programada não tenha chegado até lá. Na aglomeração densa, a abertura no ano 2000, mesmo muito restrita, de duas linhas de metrô cruzando-se no Centro suscitou entusiasmo, ao menos por seu grau de freqüência inesperado, pela modernidade do material rodante e a beleza das estaçôes transformadas em verdadeiros museus arqueológicos urbanos. Mas, em razão da aplicação de uma metodologia atrasada, tratou-se mais de um metrô com estaçōes muito próximas, portanto com velocidade comercial limitada, feito por túneis na rocha - para não perturbar os horizontes históricos - muito profundos e muito caros, portanto sem adequação com as necessidades de tráfego da região urbana. Teme-se já que os 7 milhões de deslocamentos cotidianos, dos quais $42 \%$ são ainda justificados pelos trajetos residência-trabalho, não vejam diminuir a parte do automóvel (38\%) com relação aos transportes coletivos (31\%). Trinta mil vagas de estacionamento suplementar no Centro não devem ademais desencorajar os automobilistas. Apesar do sucesso inegável do metrô, a necessidade de mobilidade e a extensão do território urbano não estariam aumentando mais rapidamente do que a eficácia da rede férrea?

É sem dúvida a lição dos melhoramentos que a preparação dos Jogos e as necessidades de servir aos diferentes espaços olímpicos deram às infra-estruturas de transporte. Fiel às lógicas circulatórias atenienses, a grande obra torna-se a organização de uma via paralela de auto-estrada em torno da cidade pelo Norte, no novo aeroporto de Eleusis (via Atiki). Na Itália teríamos falado de uma tangenziale. O investimento é gigantesco, cheio de obras de arte, remarcáveis (viadutos, túneis, desvios com as radiais principais), e comporta uma alternativa interessante em direção ao Centro de Atenas. É uma nova coluna vertebral que assim é dada à capital. Podemos nos inquietar simplesmente que ela a faça, de novo, parecer-se mais com Los Angeles do que com uma metrópole européia.

No entanto, para sacrificar o desenvolvimento durável, imaginamos modos de transporte ainda menos poluidores do que os 2 mil ônibus modernos que deveriam renovar o parque urbano. O mais visível e o mais midiático é uma linha de bonde de $27 \mathrm{~km}$ que, no bairro da Acrópole, desce em direção ao mar para se bifurcar em direção às implantações olímpicas da baía de Falero e do Aghios Kosmas. Vias gramadas calculadas para resistir aos terremotos de forte magnitude com carros desenhados por Pino Farina, nada foi poupado para fazer do bonde a chave de uma nova concepção de cidade. Mas paga-se caro para recolocar em ordem, indispensável e imprevisível, redes (eletricidade, água, esgotos), lutas contra as reticências dos habitantes dos bairros atravessados, finalmente talvez atrasos para sua implantação total na abertura dos Jogos. Ao lado, a renovação das vias férreas 
nacionais, para nelas fazer circular trens dos grandes subúrbios em direção a Tebas, Kalkis (ao Norte), Corinto (a Oeste) a 100km da Acrópole, é menos espetacular, mas sem dúvida mais promissora. Pela primeira vez, uma rede de transportes coletivos satisfaz a região metropolitana. Incontestavelmente, a dispersão das implantações olímpicas representou, senão um tratamento excelente da mobilidade ateniense, ao menos um impulso prioritário em direção a este tratamento.

De uma maneira mais geral ainda, a atmosfera urbana mudou em Atenas. As transformações mais visíveis dizem respeito aos bairros centrais, mesmo se ali a conscientização, os projetos e as primeiras tentativas tenham começado bem antes do anúncio dos Jogos. O começo longínquo poderia bem ser fixado desde 1974, quando a diáspora dos exilados políticos para a Europa ocidental (França, Alemanha) trazem de volta ao país novos modos de percepção da centralidade. Mas as realizaçóes dos últimos anos aparecem com uma amplidão inegável. A ligação para pedestres entre os diferentes sítios arqueológicos ou históricos em torno da Acrópole (Zapion, colunas de Zeus, Filopapo, Ágora, Plaka) é finalmente realizada, criando um notável espaço de paz, até mesmo de respiração, no coração da capital, e oferecendo aos atenienses e aos turistas a descoberta de um tempo milenar. Numa proximidade imediata, as grandes praças simbólicas de Atenas (Syntagma, da Constituição, Omonia, da Concorde, Monastiraki) se beneficiam com a chegada do metrô, com a valorização de prédios e hotéis de prestígio (a restauração do hotel Grande Bretagne na praça Syntagma é uma verdadeira maravilha), para reabilitar, pelo menos criar, um verdadeiro espaço público.

De fato, todo o Centro de Atenas, ruas, pracinhas, últimas construções neoclássicas do século XIX, salvas ou habilmente reconstituídas, foram objeto de um lifting urbano, que torna a cidade um canteiro de obras permanente, mas transforma também sua aparência e sua imagem. Se o aburguesamento residencial é ainda bastante limitado a alguns pequenos espaços em moda (ao pé da Acrópole e em torno do Observatório) e para alguns representantes da intelligentsia esclarecida, a frequiência social das zonas centrais é muito mais significativa. Encontrar num sábado à noite, no doce outono ateniense, grupos de jovens nos terraços dos cafés e restaurantes do velho bairro comercial, habitualmente deserto a esta hora, é um sinal evidente de reconquista urbana.

De forma compatível com a tradição ateniense das últimas décadas, o boom imobiliário incentivado pela expectativa dos Jogos beneficia também as grandes avenidas que partem do Centro e atraem as funções comerciais, tradicionais e lúdicas por várias dezenas de quilômetros: a avenida Sygrou em direção à baía do Pentélico e a avenida de Kifissia em direção ao Norte e os contrafortes aéreos do Pentélico viram multiplicarem-se os imóveis de vidro e espelhos que rivalizam com a arquitetura pós-moderna, de decoração kitsch e de natureza aprisionada, nas quais a bandeira batida dos anéis olímpicos fixa o que é preciso de fidelidade nacional e de afirmação mundial. A novidade é a valorização acelerada de localizações que, para ilustrar o duplo tropismo do mar e da montanha, não estão desta forma menos sob a influência direta dos grandes equipamentos em vias de acabamento. A frente costeira, de Falero até Vougliameni, se faz parecida com a Côte D’Azur, com o fim do aeroporto, a chegada do bonde e as instalações esportivas de Aghios Kosmas. No Norte, a comuna de Amaroussi, até então bem tranqüila, sonha ser Manhattan com a proximidade do estádio olímpico e de seus anexos.

Mas aí também, os processos de maior vulto ligam-se às grandes infra-estruturas de transporte. Bem além dos limites da cidade, a auto-estrada número 1 em direção à Tessalônica continua a atrair as firmas estrangeiras de prestígio, por vezes em antigos 
locais industriais abandonados (Siemens, Ernst \& Young, Sanofi Synthelabo, Squibb). As atrações do novo aeroporto Eleftherios Venizelos e da auto-estrada Atiki deslocam a abertura do setor terciário para a vertente de Himeto e invadem a planície agrícola do Mesogeu. E, a Oeste, a vila olímpica mexe nas dessimetrias econômicas da capital, suscitando na proximidade das regiões das auto-estradas novos centros comerciais e de negócios, seduzidos pelos baixos custos financeiros. Contrariamente ao discurso dominante, trata-se ainda da promoção da Atenas do automóvel e da via rápida; mas, tal como o que se verifica na planície Saint Denis em torno do Stade de France, trata-se de uma retomada da dessolidarização espacial entre o desenvolvimento econômico e a mistura social.

\section{O APRENDIZADO DE UMA GOVERNANÇA URBANA REGULADA?}

A capital grega certamente não esperou a voga da governança urbana para praticar com eficácia este modo de gestão dos espaços metropolitanos. Durante mais de meio século, a pressão demográfica e o enfraquecimento jurídico e financeiro do Estado resolveram-se em um consenso social generalizado para reconstruir e expandir a cidade. Densificaçōes de bairros centrais, construçōes periféricas ilegais, mas regularizadas a cada eleição, foram as expressōes maiores deste mecanismo que, certamente, desvalorizou o meio urbano, mas assegurou para milhões de atenienses residência e promoção econômica e social. A oportunidade dos Jogos Olímpicos racionalizou esta lógica específica e fez dela até mesmo uma pedagogia cívica.

A gestão política e financeira da manifestação é disto uma boa ilustração. Em razão da importância do desafio e da extrema complexidade dos poderes na capital (60 municipalidades na bacia de Ática, perto de 160 na região metropolitana, autoridades da Prefeitura, eleitas e nomeadas), é o governo, sob a égide do ministério do Meio Ambiente, Organização do Território e Obras Públicas, e de sua emanação, o Comitê dos Jogos Olímpicos 2004, que conservou o total controle técnico e financeiro das infra-estruturas públicas programadas. Ele foi o interlocutor direto do Comitê Olímpico Internacional e dos Jogos Paraolímpicos. Mesmo se a dúvida epistemológica é de rigor, o orçamento total do investimento estava estimado pelo secretário geral do Comitê, K. Kartalis, em 4,5 bilhões de euros, dos quais 3,3 a título de obrigaçóes feitas pelo Comitê Olímpico Internacional, e 1,2 bilhão suplementar de dotação voluntária do governo grego. Estas somas representariam, entre 2001 e 2004, somente 8\% do "pacote" de subvençôes da Europa à Grécia e seriam completamente cobertas por recursos nacionais. A título de comparação, as retransmissões televisivas das provas elevar-se-iam a 1,5 bilhão de euros, partilhados ao meio entre o Comitê Olímpico Internacional e a nação organizadora.

Mas diante desta centralização da decisão, uma cooperação estrutural entre os setores público e privado foi organizada. O conjunto dos grandes equipamentos abriu espaço para adjudicações a grupos privados de obras públicas, com cadernos de encargos clássicos. Mas, tendo em vista a importância das infra-estruturas, a imprevisibilidade dos financiamentos e operações técnicas a serem realizadas (reforço do solo à beira-mar para as instalaçōes da baía de Falero, deslocamentos das redes para o estabelecimento do bonde), a urgência incontornável da entrega das obras, formas originais de colaboração e de decisão tiveram que ser imaginadas: aceleração dos mecanismos de mercados, autonomia 
de ação dos responsáveis pelos canteiros de obras que devem enfrentar, em procedimentos de urgência, as queixas à polícia e os processos judiciais, criação sob a batuta do ministério do Meio Ambiente de uma Real Estate Company Olympic Properties para as aquisições fundiárias. Esperou-se de tudo isso uma nova cultura do management público, muito enfraquecido na Grécia até agora. É prematuro estimar as conseqüências reais dessas expectativas, da mesma forma que os retornos esperados dos investimentos, imediatos para as sociedades adjudicatárias, mas em prazo muito mais longo para a cidade.

De modo muito mais geral ainda, esperou-se que a preparação e a realização dos Jogos viessem representar para a sociedade ateniense e grega um verdadeiro aprendizado do espaço público e do interesse coletivo, que foram os grandes ausentes do "urbanismo espontâneo" do último meio século. O respeito das calçadas, das ruas de pedestres, a criação de passeios e parques, a adoção de novos modos de transporte (metrô, bonde) deveriam ser mediaçõos materiais para a criação de uma mentalidade cívica, para não dizer de um espírito democrático, à medida dos desafios do século XXI.

Enfim, a preparação dos Jogos Olímpicos mostrou as deficiências relativas à ausência de um verdadeiro governo metropolitano: superposição de autoridades e competências, decisões apressadas e pouco coordenadas. Desde a primavera de 2003, de acordo com as diretrizes da OCDE (Organisation for Economic Co-operation and Development) sobre governança, um grupo de trabalho foi constituído - o Team Attica Athens - entre o Ministério do Interior e a União das Autoridades Locais para refletir conjuntamente sobre um plano estratégico de crescimento metropolitano orientado ao desenvolvimento econômico e ao papel que a Ática deveria desempenhar na ampliação européia, notadamente nos Bálcãs e no Leste europeu. Não se pode mostrar melhor o choque que os Jogos Olímpicos produziram na capital grega: uma reformulação de sua materialidade, uma reafirmação de sua vocação mundial.

As luzes da festa mal se apagaram. É muito cedo para fazer o balanço das conseqüências dos Jogos. Mas, para além do despertar incontestável do investimento e da consciência urbana, questóes permaneceram abertas. $\mathrm{O}$ sucesso imediato das manifestações de agosto de 2004 (término dos canteiros de obras, afluência, segurança) foi evidentemente um primeiro teste. A rentabilidade econômica das infra-estruturas e dos equipamentos deverá ser ainda acompanhada, mesmo que ela só possa ser estabelecida a médio e longo prazo. Mas as interrogações parecem ainda mais fundamentais. A capacidade de Atenas de continuar a ser um cruzamento de integração social e econômica pode se revelar claramente a partir desse evento. Ele mobilizou certamente várias centenas de milhares de trabalhadores, legais ou clandestinos, de nacionalidades múltiplas. O espaço residencial e profissional da capital poderá integrá-los de forma durável? A resposta depende em parte da capacidade de repercussão do lúdico e do cultural sobre a competitividade econômica global da cidade. Neste combate aberto, o governo democrático da metrópole, para a determinação de seus objetivos assim como para a repartição de seus benefícios, é evidentemente uma chave essencial.

\section{REFERÊNCIAS BIBLIOGRÁFICAS}

BURGEL, G. Le miracle athénien au XXème siècle. CNRS Éditions, 2002.

. La ville contemporaine de la Seconde Guerre mondiale à nos jours. In: PINOL, J.-L. (Dir.) Histoire de l'Europe urbaine. Seuil, 2003. 


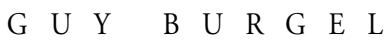

BURGEL, G.; DEMATHAS, Z. (Dirs.) La Grèce face au troisième millénaire, territoire, économie, société, 40 ans de mutations. Laboratoire de Géographie Urbaine, Université de Paris X, Université Pantios, Athènes, 2001.

ROUSSET-DESCHAMPS, M. (Dir.) Gouverner les métropoles. Laboratoire de Géographie Urbaine, Université Paris X, Villes en Parallèle, n.30-1, 2000.

A B S T R A C T The 2004 Olympic Games marked the top of a new era opened at the Greek capital twenty five years ago. The reestablishment of a reinforced democracy, the attachment to Europe, the consciousness of its international responsibility at the East Mediterranean region, at the Balkans and around the world through its merchant marine, affirm Athens in its route to a "global city". Besides the issue of functionality regarding the competitions and celebrations, the choice of the Olympic sites responded to a strategic will of reconverting the infra-structures after the Games in the benefit of the whole urban region. This article shows that, more than in Barcelona, where the city's move towards the harbor was the main event of the 90s; the change in Athens has been more fundamental, since this continental capital has never been a coastal city: since the Antiquity, the Pireu and its basins constituted a maritime entry and the vocation of the coast has ever been more balneary than truly urban.

K E Y W O R D S Athens; Olympic Games; urbanism. 